\title{
The Value of China Steam Coal Supply Chain Information Sharing and Impact of Lead-Time and Seasonal Factor
}

\author{
Li Yang ${ }^{1,2}$,Dong Mu ${ }^{1}$ and Chao Wang ${ }^{3}$ \\ ${ }^{1}$ College of Economics and Management, Beijing Jiaotong University (China) \\ ${ }^{2}$ College of Management, Inner Mongolia University of technology (China) \\ ${ }^{3}$ College of Economics and Management, Beijing University of Technology \\ (China) \\ ${ }^{1}$ linda_nm@163.com, ${ }^{2}$ mueast@163.com, ${ }^{3}$ cwang@bjut.edu.cn
}

\begin{abstract}
The steam coal supply chain has the problem that the member's inventory level cannot change with the market demand. The main reason is that market demand information has not been shared in the supply chain members. This paper considers the steam coal supply chain which consists of one coal manufacturer and one fire power plant, with the assumption that the steam coal demand follows a seasonal autoregressive moving average process, including marketing actions that cannot be deduced form the other parameters of the demand process. We compare the optimal inventory level of the steam coal manufacturer and the power plant in two scenarios and analyses the reasons that influence the value of the information sharing in the steam coal supply chain. It demonstrates that the seasonal effect and lead-time have an important impact on optimal inventory policy. This result provides managers of steam coal manufacturers and power plant with insights to establish strategic partnership to promote the performance of the whole supply chain.
\end{abstract}

Keywords: Steam coal, Supply chain, Information sharing, Seasonal demand

\section{Introduction}

\subsection{Research Background}

China's coal demand accounts for half of the global coal market demand. As the major energy, coal plays an important role in china's economy. The steam coal takes a major part of the coal consumption in china. The majority coal reserves lie in the west-central provinces of Shaanxi, Shanxi, Inner Mongolia as well as Xinjiang in china. While most demand areas lie in the south-east coastal regions. When the coal transport from north to south exists many uncertainties. Due to the reason of demand uncertainty and transportation uncertainty steam coal supply chain partners reserve lots of coal inventory to meet the fluctuation of the demand. Along the steam coal supply chain demand has been exaggerated that leads to the high inventory. The high inventory level increases the inventory cost. High cost reduces the profit of the power plant. How to affiliate the bullwhip effect has been critical to cut down the cost of steam coal supply chain. As many researchers found that information sharing has been regarded as the best way to affiliate the demand exaggeration, while how the information sharing influence the steam coal supply chain has not been studied yet. Different with other manufacture supply chain, steam coal supply chain has been influenced by the macroeconomics and the development of electricity and steel industry greatly. The steam coal supply chain consist of the major coal mining manufacturer, coal mine and fire power plant or steel manufacturer. The upper coal mining manufacturer has few influence of the whole supply chain. The difference between steam coal supply chain with non steam coal supply chain is the 
demand stability; the non-steam coal supply chain which faces stable demand with stochastic fluctuation. Ganesh, Raghunathan \& Rajendran (2014) find the value of information sharing is small when demand is stable, so this literature concerns the value of information sharing in steam coal supply chain.

In the big data age, information sharing has been drawing heightened attention from practitioners and researchers ( $\mathrm{Li} \&$ Zhang, 2015). Fierce competition and advent of information technology promote the cooperation of companies in the supply chain (Ha \& Tong, 2008), information sharing is viewed as one of the key elements for successful supply chain management and coordination. Information sharing can reduce the risk brought by asymmetric incomplete information ,cut down lead time ,mitigate bullwhip effect and reduce total cost and increase total supply chain profit (Ganesh et al., 2014; Li \& Zhang, 2008; Lee, 2000). The global performance of a supply chain can be highly improved by information sharing between its members at different levels (MontoyaTorres \& Ortiz-Vargas, 2014).

Steam coal demand is influenced by the seasonal factor. In the winter fire coal demand increase dramatically while in spring the steam coal demand is stable, with the temperature increases demand of electric power increases. So the demand of steam coal fluctuated with the season. To cope with these demand fluctuation the port, power plants reserve huge steam coal inventory. Steam coal is very metamorphic so it cannot be reserved for a long time in large scale. Through information sharing deciding the reasonable inventory level, especially when the seasonal phenomenon occurs is the main purpose of this paper.

In this paper, we evaluate the value of information sharing in a two-echelon steam coal supply chain that consists of one coal manufacture and one power plant. The power plant gathered the information of steam coal demand then he made a choice whether to share it with the supplier, if he shared the demand information with manufacture then the supplier would guarantee sustainable coal supply. To compare inventory levels in information sharing scenario with non information sharing scenario, and find out how the lead-time, seasonal factor influence the value of information sharing.

The paper makes the following contributions: (1) the seasonal factor has impact on average manufacturer's inventory level. (2) relationship of the seasonal factor and the lead-time influence the average manufacturer's inventory level. The paper is organized as follows. In section 2, relevant literature review has been done. Section 3 describes the modeling framework, and section 4 derives the optimal steam coal inventory policies under the two scenarios. Then, in section 5 we evaluate the impact of information sharing on the inventory of the coal manufacturer. The results of the numerical experiments are presented in section 6 . In section 7 we concluded the paper and pointed out the insights of this study.

\subsection{Literature Review}

Information sharing can reduce the risk brought by asymmetric incomplete information, cut down lead time, mitigate bullwhip effect (Ganesh et. al., 2014; Li \& Zhang, 2008; Lee, 2000). Many research concerns the reason of bullwhip effect. Information sharing can alleviate the bullwhip effect but cannot eliminate it. The bullwhip effect still remained due to the fact that buyers and sellers, despite achieving information transparency, often regulate their inventory control and material flow by using classical decision rules that create distorted information in the supply chain (Cannella, 2014). In spite of the benefits of information sharing, few organizations practice it .So Li \& Zhang (2015) studied the incentive of information sharing. When the manufacture make the decision of price and inventory, the supply chain information sharing can benefit all the supply chain, because the decision on the inventory level can helps the supply chain build enough stock to avoid missing an optimistic demand market. Ryu, Tsukishima \& Onari 
(2009) found that the enrichment of information will change the nature of bullwhip effect from geometrical to linear.

In the period of 1982-1996 literatures concerned horizontal information sharing. Since 2000 there were many literatures concern vertical information sharing. Li \& Zhang (2008) studied vertical information sharing between one manufacturer and several retailers which compete in price. They found confidentiality has value to the retailers and make the supply chain more efficient as a whole. Shamir (2012) focused on horizontal information sharing. In order to induce the truthful cost information sharing the retailer needs to share it with manufacture as well. Bian, Guo, Lai \& Hua (2014) discusses the strategic effects of bilateral information sharing in a vertical-Nash supply chain. Information sharing can be detrimental to both channel members specifically if the forecasts of the manufacturer and retailer are not sufficiently differentiated.

Ha \& Tong (2008) studied two competing supply chains each consist of one manufacturer and one retailer. They were identical except the cost investment for information sharing. The demand state is only two states, low and high. Investment cost and contract type are key factors for information sharing decisions in supply chain. Ha, Tong \& Zhang (2011) studied the diseconomies of scale, information accuracy, competition intensity, the type of competition affect the value of information sharing in two compete supply chains. The retailers sell substitutable products in the same market with uncertain demand. Each retailer has some private and imperfect information about the demand. In the case of Bertrand competition information sharing make demand more variable for both supply chains. Information sharing made retail quantity less variable but the rival supply chain more variable. Li, Gilbert \& Lai(2014) studied the supply chain that reseller knew the realization of the market size but the encroaching supplier knew only the prior distribution of the market. The supplier wanted to infer the true size of the market according to the order but the retailer has the incentive to distort the order quantity for his own benefit. The supplier would prefer to sell it to a better-informed reseller when her efficiency disadvantage in the selling process is not large.

Li \& Lin (2006) empirically examined the impact of trust partnership and shared vision on information sharing in supply chain. Youn, Yang, Kim \& Hong (2014) examined supply chain information capabilities and firm competitive advantage. Information sharing always involves cost. Whether the retail revealed information to the manufacturer depended on the cost and demand signal. With the high demand and low cost the retailer would sharing correct information with the manufacture (Chu \& Lee, 2006). Effective information sharing significantly enhanced effective supply chain practice (Zhou \& Benton, 2007).

Cho (2013) evaluated the value of information sharing was sensitive to the change of seasonal phenomenon. Cho's study concerned the retail supply chain but ours concern the steam coal supply chain. Helper, Davis \& Wei (2010) considered the supply chain information sharing value affected by the capacity constraints. Retailers could benefit higher than supplier when the supplier's capacity is constrained. When the supplier had ample capacity the supplier benefited more. Shamir (2012) asserted complex nature of a supply chain could facilitate information-sharing in settings of asymmetric information. Some obstacles existed in creating information sharing agreement first in equilibrium each firm must be better off sharing information than concealing it. Shnaiderman \& Ouardighi (2014) determined how intermediate levels of information sharing between supply chain members influenced their total costs. Supply chain partners may have to forecast their market demands based on incomplete information ( $\mathrm{Wu}$, Chuang \& Hsu, 2014). Over reliance on the technical issue without a willingness to share information for critical activities creates a problem for partners with meaningless connection. Ganesh et. al., (2014) revealed that ignoring product substitution can lead to a significant overestimation of value of information sharing especially for firms that are more upstream in the supply chain. The degree of retail competition, the relative precision 
of a retailer's stochastic signals, and whether competing retailers are already sharing signals are three important factors determine the benefits of vertical information sharing (Gal-Or, Geylani \& Dukes, 2008).

While incentive for information sharing are still an issue (Li \& Zhang, 2015).Tang (2000) found supply chain information sharing could provide significant inventory reduction, cost savings to the manufacture and processing costs reduction, lead-time to the retailer's. They studied the demand correlation and lead-time how influences the benefits of information sharing. Especially manufacture gets the most benefits when the demand is highly correlated, highly variable or the lead-time is long. While Raghunathan (2001) found when the manufacture could deduce the parameters of the demand according to the history order, the value of information sharing decreased dramatically to the manufacture. Bai(2015) concerns the effect of autoregressive parameter with information sharing value. Yan(2015) reveals that the information sharing has no uniform effect on firm performance, the value of information sharing under various circumstances need further study. Most information sharing research concern the retail field or the high tech industry, they had identical products or the retailer compete in price or quantity. The steam coal as industrial fuel did not like the retail product; the study of steam coal supply chain information sharing is different from the other studies.

To our knowledge there are few studies about the steam coal supply chain information sharing. Kuby, Ratick \& Osleeb (1991) developed a network-optimization planning methodology for U.S. coal port infrastructure. Zaklan, Cullmann, Neumann \& Von Hirschhausen (2012) studied how steam coal logistics affect the steam coal trade through the price including the cost of railway, sea transport and transportation to the final customer. Because the steam coal is not easily standardized, the steam coal supply chain has not got much attention of the researchers. However, as the major energy of the world, steam coal supply chain effective management is very important, especially how to reduce the bullwhip effect and the cost of the steam coal supply chain.

\section{Modeling Framework}

We consider a two-echelon steam coal supply chain which consists of one steam coal manufacture and one power plant. The power plant follows an order-up-to level periodic review policy to review his steam coal inventory and order from coal manufacture.

Let $s_{t}, t=1,2,3, \cdots$ denote the power plant order-up-to level. At the end of time period $t$, the power plant orders $Y_{t}$, where

$Y_{t}=D_{t}+S_{t}-S_{t-1}$

That means the order quantity $Y_{t}$ is need to cover the demand of period $t$ and the change of order-up-to level of period $t-1$ and $t, S_{t}$ is the power plant order-up-to level of period $t$.

The power plant faces the seasonal steam coal demand

$$
D_{t}=\varphi_{0}+\varphi_{1} D_{t-1}+\varepsilon_{t}-\gamma \varepsilon_{t-s}
$$

Where

$D_{t}$ - the observed steam coal demand of period $t$;

$\varphi_{0}$ - the average steam coal demand estimation;

$\varphi_{1}-$ degree of correlation between the steam coal demand at the present period and the demand at the previous period;

$\gamma$ - degree of correlation between the steam coal demand at the present period and the demand at the previous seasonal period $s, s=1,2, \ldots$; 
$\varepsilon_{t}-$ error term is i.i.d. normally distributed with mean zero and variance $\sigma^{2}$, as( Lee \& Whang, 2000; Cho, 2013), it is assumed that $\sigma$ is smaller than $\varphi_{0}$, so that the probability of a negative demand is negligible.

There is no fixed order cost; $h$ and $p$ denote the unit holding and shortage costs per time period at the steam coal manufacturer and power plant, respectively. $p$ stands for power plant, $m$ stands for steam coal manufacturer.

\section{Optimal Inventory Policies}

\subsection{Optimal Inventory Policy of the Power Plant}

The power plant order decision is to meet the electricity demand and the change of the inventory order-up-to level. We need to decide the optimal order-up-to level $S_{t}^{*}$ that minimizes the total expected holding and shortage costs in period $t+l+1$. Using the recursive relationship of $D_{t}$ given in (2.2), we have

$$
\begin{array}{ll}
\begin{array}{ll}
\sum_{i=1}^{l+1} D_{t+i}= & \frac{1}{1-\varphi_{1}}\left\{\varphi_{0} \sum_{i=1}^{l+1}\left(1-\varphi_{1}^{i}\right)+\varphi_{1}\left(1-\varphi_{1}^{l+1}\right) D_{t}\right\} \\
& +\varepsilon_{l+1}+\left(1+\varphi_{1}\right) \varepsilon_{l}+\cdots+\left(1+\varphi_{1}+\varphi_{1}^{2}+\cdots+\varphi_{1}^{l}\right) \varepsilon_{t+1} \\
-\gamma \varepsilon_{l+1-s}-\gamma\left(1+\varphi_{1}\right) \varepsilon_{l-s}-\cdots-\gamma\left(1+\varphi_{1}+\varphi_{1}^{2}+\cdots+\varphi_{1}^{l}\right) \varepsilon_{t+1-s}
\end{array} \\
\text { Let } \quad m_{t}^{p}=E\left[\sum_{i=1}^{l+1} D_{t+i} \mid D_{t}\right] \\
\text { And } \quad v_{t}^{p}=\operatorname{Var}\left[\sum_{i=1}^{l+1} D_{t+i} \mid D_{t}\right]
\end{array}
$$

be the conditional expectation and the conditional variance of $\sum_{i=1}^{l+1} D_{t+i}$ respectively. Then

$$
\begin{aligned}
& m_{t}^{P}=\frac{\varphi_{0}}{1-\varphi_{1}}\left\{(l+1)-\sum_{j=1}^{l+1} \varphi_{1}^{j}\right\}+\frac{\varphi_{1}\left(1-\varphi_{1}^{l+1}\right)}{1-\varphi_{1}} D_{t} \\
& v_{t}^{p}=\frac{\sigma^{2}}{\left(1-\varphi_{1}^{2}\right)} \sum_{j=0}^{l}\left(1-\varphi_{1}^{j+1}\right)^{2}
\end{aligned}
$$

Therefore the optimal order-up-to level $S_{t}^{p^{*}}$ of the power plant at time $t$ is

$$
S_{t}^{p^{*}}=m_{t}^{p}+k_{p} \sqrt{v_{t}^{p}}
$$

Where $k_{p}=\varphi^{-1}\left[p_{P} /\left(p_{P}+h_{P}\right)\right]$ for the standard normal distribution function $\phi$.

\subsection{Optimal Inventory Policy of the Steam Coal Manufacturer}

The manufacturer faces and meets the order of the power plant by his inventory. If there are not enough inventories to meet the order, the manufacturer needs to manufacture the coal. The production time is $L$, then from (2.1) and (3.2), we have

$$
Y_{t}=D_{t}+\frac{\varphi_{1}\left(1+\varphi_{1}^{l+1}\right)}{1-\varphi_{1}}\left(D_{t}-D_{t-1}\right)
$$


The manufacturer can deduce from (3.5) and (2.2) that:

$$
Y_{t+1}=\varphi_{0}+\varphi_{1} Y_{t}+\frac{1-\varphi_{1}^{l+2}}{1-\varphi_{1}} \varepsilon_{t+1}-\gamma \frac{1-\varphi_{1}^{l+2}}{1-\varphi_{1}} \varepsilon_{t+1-s}-\frac{\varphi_{1}\left(1-\varphi_{1}^{l+1}\right)}{1-\varphi_{1}} \varepsilon_{t}+\gamma \frac{\varphi_{1}\left(1-\varphi_{1}^{l}\right)}{1-\varphi_{1}} \varepsilon_{t-s}
$$

Repeated use of (3.6) yields:

$$
\begin{aligned}
Y_{t+i}= & \varphi_{0} \frac{1-\varphi_{1}^{i}}{1-\varphi_{1}}+\varphi_{1}^{i} Y_{t}+\frac{1-\varphi_{1}^{l+2}}{1-\varphi_{1}} \varepsilon_{t+i}+\sum_{k=1}^{i-1} \varphi_{1}^{l+1+k} \varepsilon_{t+i-k} \\
& -\frac{\varphi_{1}^{i}\left(1-\varphi_{1}^{l+1}\right)}{1-\varphi_{1}} \varepsilon_{t}-\gamma \frac{1-\varphi_{1}^{l+2}}{1-\varphi_{1}} \varepsilon_{t+i-s}+\sum_{j=0}^{i-1} \frac{\gamma \varphi_{1}^{j}\left(1-\varphi_{1}^{l+j}\right)}{1-\varphi_{1}} \varepsilon_{t+j-s}
\end{aligned}
$$

If there hasn't got enough stock to meet the power plant's demand, the coal manufacture needed to continue to produce more.

$$
\begin{aligned}
\sum_{i=1}^{L+1} Y_{t+i} & =\left(L+1-\frac{\left(1-\varphi_{1}^{L+1}\right) \varphi_{1}}{1-\varphi_{1}}\right) \frac{\varphi_{0}}{1-\varphi_{1}}+\frac{\left(1-\varphi_{1}^{L+1}\right)}{1-\varphi_{1}} \varphi_{1} Y_{t} \\
& +\frac{1-\varphi_{1}^{l+2}}{1-\varphi_{1}} \sum_{i=1}^{L+1} \varepsilon_{t+i}+\sum_{j=1}^{L+1} \sum_{k=1}^{i-1} \varphi_{1}^{l+1+k} \varepsilon_{t+i-k}-\frac{\left(1-\varphi_{1}^{l+1}\right)\left(1-\varphi_{1}^{L+1}\right)}{\left(1-\varphi_{1}\right)^{2}} \varepsilon_{t} \\
& -\gamma \frac{1-\varphi_{1}^{l+2}}{1-\varphi_{1}} \sum_{i=1}^{L+1} \varepsilon_{t+i-s}+\frac{\gamma}{1-\varphi_{1}} \sum_{i=1}^{L+1} \sum_{j=0}^{i-1} \varphi_{1}^{j}\left(1-\varphi_{1}^{l+j}\right) \varepsilon_{t+j-s}
\end{aligned}
$$

Scenario 1: There is no information sharing between the steam coal manufacturer and the power plant. The steam coal manufacturer knows nothing except the power plant's order size $Y_{t}$, when the manufacturer determines its optimal inventory level.

are unknown to the manufacturer.

$$
\begin{gathered}
\varepsilon_{t+i}(i=1,2, \cdots, L+1), \\
\varepsilon_{t+j-s}(i=1,2, \cdots, L+1),
\end{gathered}
$$

Let

$$
m_{t}^{m_{1}}=E\left[\sum_{i=1}^{L+1} Y_{t+i} \mid Y_{t}\right]
$$

And

$$
v_{t}^{m_{1}}=\operatorname{Var}\left[\sum_{i=1}^{L+1} Y_{t+i} \mid Y_{t}\right]
$$

be the conditional expectation and conditional variance of $\sum_{i=1}^{L+1} Y_{t+i}$ respectively then,

$m_{t}^{m_{1}}=\left(L+1-\frac{\left(1-\varphi_{1}^{L+1}\right) \varphi_{1}}{1-\varphi_{1}}\right) \frac{\varphi_{0}}{1-\varphi_{1}}+\frac{\left(1-\varphi_{1}^{L+1}\right) \varphi_{1}}{1-\varphi_{1}} Y_{t}$

If $L>s$, then 


$$
v_{t}^{m_{1}}=\sigma^{2}\left\{\begin{array}{l}
\frac{\left(1-\varphi_{1}^{l+2}\right)^{2}}{\left(1-\varphi_{1}\right)^{2}}(L+1)+\varphi_{1}^{2 l+2} \sum_{i=1}^{L+1}\left(\sum_{k=1}^{i-1} \varphi_{1}^{k}\right)^{2} \\
+\frac{\left(1-\varphi_{1}^{l+1}\right)^{2}\left(1-\varphi_{1}^{L+1}\right)^{2}}{\left(1-\varphi_{1}\right)^{4}}+\gamma^{2} \frac{\left(1-\varphi_{1}^{l+2}\right)^{2}}{\left(1-\varphi_{1}\right)^{2}}(L+1-s) \\
+\frac{\gamma^{2}}{\left(1-\varphi_{1}\right)^{2}}\left(\sum_{i=1}^{L+1} \sum_{j=0}^{i-1} \varphi_{1}^{j}\left(1-\varphi_{1}^{l+j}\right)\right)^{2}
\end{array}\right\}
$$

If $L \leq s$, then

$$
v_{t}^{m_{1}}=\sigma^{2}\left\{\begin{array}{l}
\frac{\left(1-\varphi_{1}^{l+2}\right)^{2}}{\left(1-\varphi_{1}\right)^{2}}(L+1)+\varphi_{1}^{2 l+2} \sum_{i=1}^{L+1}\left(\sum_{k=1}^{i-1} \varphi_{1}^{k}\right)^{2} \\
+\frac{\left(1-\varphi_{1}^{l+1}\right)^{2}\left(1-\varphi_{1}^{L+1}\right)^{2}}{\left(1-\varphi_{1}\right)^{4}}+\gamma^{2} \frac{\left(1-\varphi_{1}^{l+2}\right)^{2}}{\left(1-\varphi_{1}\right)^{2}}
\end{array}\right\}
$$

The optimal inventory level of the steam coal manufacturer is

$$
s_{t}^{m_{1}}=m_{t}^{m_{1}}+k_{m} \sqrt{v_{t}^{m_{1}}},
$$

where

$$
k_{m}=\phi^{-1}\left[p_{m} /\left(p_{m}+h_{m}\right)\right]
$$

for the standard normal distribution function $\phi$.

Scenario 2: The steam coal manufacturer and the power plant share not only the order information but also the demand forecast information. Thus the steam coal manufacturer make the planning according to the power plant's order $Y_{t}$ and the steam coal demand information $D_{t}$, then the steam coal manufacturer knows $\varepsilon_{t+i-s}(i=1,2, \cdots, L, L<S) \varepsilon_{t}$.

However, $\varepsilon_{t+i}, \varepsilon_{t+i-s}(i=1,2, \cdots, L, L>S)$ are still not known. So we have

$$
\begin{aligned}
m_{t}^{m_{2}} & =\left(L+1-\frac{\left(1-\varphi_{1}^{L+1}\right) \varphi_{1}}{1-\varphi_{1}}\right) \frac{\varphi_{0}}{1-\varphi_{1}}+\frac{\left(1-\varphi_{1}^{L+1}\right) \varphi_{1}}{1-\varphi_{1}} Y_{t}-\frac{\left(1-\varphi_{1}^{l+1}\right)\left(1-\varphi_{1}^{L+1}\right)}{\left(1-\varphi_{1}\right)^{2}} \varepsilon_{t} \\
& -\gamma \frac{1-\varphi_{1}^{l+2}}{1-\varphi_{1}} \sum_{i=1}^{L+1-s} \varepsilon_{t+i-s}+\frac{\gamma}{1-\varphi_{1}} \sum_{i=1}^{L+1-S} \sum_{j=0}^{i-1} \varphi_{1}^{j}\left(1-\varphi_{1}^{L+j}\right) \varepsilon_{t+j-s}
\end{aligned}
$$

If $L>s$, then

$$
v_{t}^{m_{1}}=\sigma^{2}\left\{\begin{array}{l}
\frac{\left(1-\varphi_{1}^{l+2}\right)^{2}}{\left(1-\varphi_{1}\right)}(L+1)+\gamma^{2}\left(\frac{1-\varphi_{1}^{l+2}}{1-\varphi_{1}}\right)(L+1-S) \\
+\frac{\gamma^{2}}{\left(1-\varphi_{1}\right)^{2}}\left(\sum_{i=1}^{L+1} \sum_{j=0}^{i-1} \varphi_{1}^{j}\left(1-\varphi_{1}^{l+j}\right)\right)^{2}
\end{array}\right\}
$$

If $L \leq s$, then

$$
v_{t}^{m_{2}}=\left\{\left(\frac{1-\varphi_{1}^{l+2}}{1-\varphi_{1}}\right)^{2}(L+1)\right\} \sigma^{2}
$$


The optimal inventory level of the steam coal manufacturer is

$$
S_{t}^{m_{2}}=m_{t}^{m_{2}}+k_{m} \sqrt{v_{t}^{m_{2}}}
$$

Where

$$
k_{m}=\phi^{-1}\left[p_{m} /\left(p_{m}+h_{m}\right)\right]
$$

for the standard normal distribution function $\phi$.

\section{Benefits of Information Sharing in Steam Coal Supply Chain}

We use the average inventory level discussed in (Silver \& Peterson, 1985).The steam coal manufacturer average inventory level can be approximated by

$$
\begin{aligned}
& I_{t}=\left\{s_{t}-E\left(\sum_{i=1}^{L+1} Y_{t+i}\right)+E\left(Y_{t}\right) / 2\right\}=\left\{s_{t}-m_{t}+E\left(Y_{t}\right) / 2\right\} \\
& I_{t}^{m_{1}}=S_{t}^{m_{1}}-m_{t}^{m_{1}}+E\left(Y_{t}\right) / 2=k_{m} \sqrt{v_{t}^{m_{1}}}+\frac{\varphi_{0}}{2\left(1-\varphi_{1}\right)} \\
& I_{t}^{m_{2}}=S_{t}^{m_{2}}-m_{t}^{m_{2}}+E\left(Y_{t}\right) / 2=k_{m} \sqrt{v_{t}^{m_{2}}}+\frac{\varphi_{0}}{2\left(1-\varphi_{1}\right)}
\end{aligned}
$$

$v_{t}^{m_{2}}<v_{t}^{m_{1}}$, therefore, $I_{t}^{m_{2}}<I_{t}^{m_{1}}$ information sharing can reduce the manufacturer's inventory level.

$$
I_{t}^{m}=I_{t}^{m_{1}}-I_{t}^{m_{2}}
$$

Proposition 1:

For $0 \leq \varphi_{1} \leq 1$ and $-1 \leq \gamma \leq 1, I_{t}^{m}$ increases as $L, l$ increase,

For $0 \leq \varphi_{1} \leq 1, I_{t}^{m}$ decreases as $\gamma$ increases,

For $-1 \leq \gamma \leq 1, I_{t}^{m}$ increases as $\varphi_{1}$ increases.

Proposition2:

$v_{t}^{m}$ is the smallest when the coal manufacturer and the steam plant sharing information as well as $L \leq S$.

\section{Numerical Analysis}

We examine the autoregressive coefficient $\varphi_{1}$ influence the magnitude of inventory reductions for the manufacturer in two scenarios. The parameter values are given as $p_{m}=19, h_{m}=1, \gamma=0.8, l=0, L=10, \sigma=1 . \quad p_{m}, h_{m}$ denote the unit holding and shortage costs per time period at the steam coal manufacturer. $\gamma=0.8$ means the high degree of correlation between the steam coal demand at the present period and the demand at the previous seasonal period s. $\sigma=1$ means the error term is i.i.d. normally distributed with mean zero and variance 1 .

Figure 1, illustrated the impact of $\varphi_{1}$ on inventory reduction of the manufacturer. The inventory reduction is increases as the absolute value of $\varphi_{1}$ increases. When the $\varphi_{1}$ close to zero the inventory reduction is close to zero, so the value to information sharing is close to zero when the $\varphi_{1}$ is close to zero. The same result reached as (Lee \& Whang, 2000). That means when the steam coal supply chain demand has much uncertainty, the more value of information sharing in supply chain members, so study the information sharing in the steam coal supply chain is meaningful. 


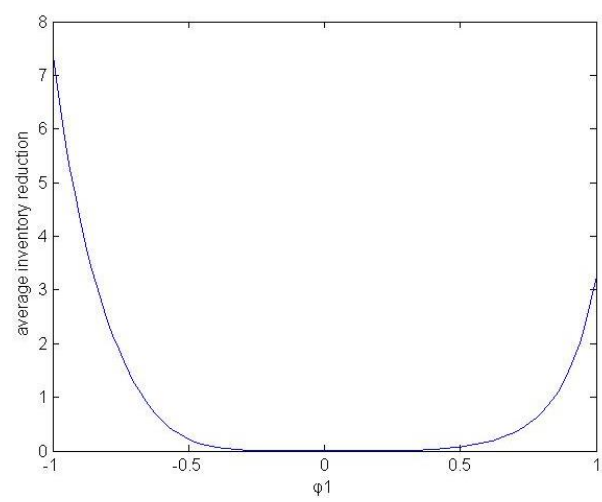

Figure 1. Impact of $\varphi_{1}$ on Average Manufacturer's Inventory Reduction

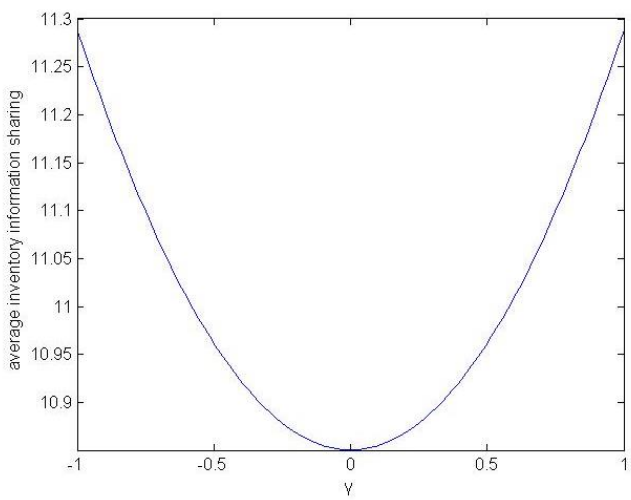

Figure 2. Impact of $\gamma$ on Average Manufacturer's Inventory Reduction

Figure 2, illustrates the impact of $\gamma$ on average inventory sharing information, we observe that the average inventory increases when the absolute value of $\gamma$ increases. We shift the seasonal factor $S$ to examine how the parameter affects the magnitude of inventory reduction for the coal manufacturer in case of $L>S$ and $L<S$. The parameter values are given as $p_{m}=19, h_{m}=1, \gamma=0.8, l=0, L=13, \sigma=1, \varphi_{1}=0.8$. In case of $L>S$, Figure 3, illustrates the results of the impact of $S$ on the coal manufacturer inventory level. The inventory level is decreasing as the $s$ increasing. In the scenario of information sharing the inventory level is lower than the non information sharing scenario. The decreasing of the inventory level is much quicker with information sharing than non information sharing.

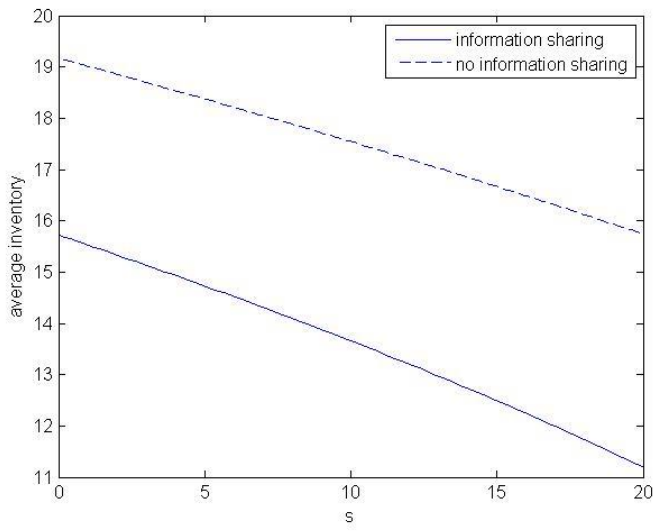

Figure 3. Impact of $s$ on Average Manufacturer's Inventory in Case of I>S 
In case of $L \leq S$, the seasonal factor does not have any impact on average manufacturer's inventory. Figure 4, illustrates the coal manufacturer's inventory doesn't changed when the seasonal factor change.

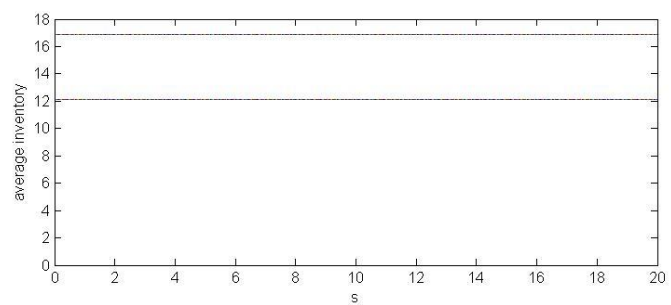

Figure 4. impact of $S$ on Average Manufacturer's Inventory in Case of $L<S$

The numerical experiments show the sensitivity of the average manufacturer inventory. We find that the seasonal factor and the relation with the lead-time have impact on the average manufacturer inventory. Information sharing can reduce the average inventory level no matter the seasonal factor works.

\section{Conclusion and Insight}

This paper evaluates the value of information sharing in the two-echelon steam coal supply chain which consists of one coal manufacturer and one power plant. The means and variances of the coal manufacturer's order quantity for two levels of information sharing is considered and the optimal inventory policies is obtained. It shows that the coefficient has impact on the average manufacturer's inventory. That means information sharing has great value when steam coal demand has much uncertainty. In the steam coal supply chain, demand is not stable so that it is necessary to improve the whole performance of the supply chain from sharing steam coal demand information. It also shows that the lead-time and the seasonal factor have impact on the average manufacturer's inventory. Information sharing can decrease the average inventory level of the coal manufacturer. The value of information sharing in steam coal supply chain is sensitive to the change of seasonal phenomenon, so the managers pay attention to the seasonal factor especially when the lead-time is longer than the seasonal period. In the steam coal supply chain lead-time does not like the retail industry; there are more uncertainty in production and transportation. So the lead-time always takes much time. When the lead-time is longer than seasonal period, the value of information sharing in the steam coal supply chain is more significant. In the steam coal supply chain information sharing haven't got much attention from the practitioner, our work give some light on the information sharing value in the energy supply chain.

For more investigation of the value of information sharing in the steam coal supply chain, one may need to extend the research to the cases of more complicated supply chain. Next step is to study the incentives of information sharing in the steam coal supply chain and coordination of the supply chain.

\section{Acknowledgements}

This study was supported by the key program of National Natural Science Fund (Grant No71132008), program of Natural Science Fund in Inner Mongolia Autonomous Region (Grant No 2015MS0704 ), scientific research program of institutions of higher learning in Inner Mongolia Autonomous Region (Grant No NJSY14073). 


\section{References}

[1] M. Ganesh, S. Raghunathan and C. Rajendran, "The value of information sharing in a multi-product, multi-level supply chain: Impact of product substitution", demand correlation, and partial information sharing.Decision Support Systems, doi:10.1016/j.ijpe.2015.05.020, vol. 58, (2014), pp. 79-94.

[2] T. Li and H. Zhang, "Information sharing in a supply chain with a make-to-stock manufacturer", Omega,. doi:10.1016/j.omega.2014.08.001, vol. 50, (2015), pp. 115-125.

[3] A. Y. Ha and S. Tong, "Contracting and information sharing under supply chain competition. Management science",. http://dx.doi.org/10.1287/mnsc.1070.0795, vol. 54, no. 4, (2008), pp. 701-715.

[4] M. Ganesh, S. Raghunathan and C. Rajendran, "The value of information sharing in a multi-product, multi-level supply chain: Impact of product substitution, demand correlation, and partial information sharing”, Decision Support Systems,. doi:10.1016/j.dss.2013.01.012, vol. 58 (2014), pp. 79-94.

[5] L. Li and H. Zhang, "Confidentiality and information sharing in supply chain coordination", Management science,. http://dx.doi.org/10.1287/mnsc.1070.0851, vol. 54, no. 8, (2008), pp. 1467-1481.

[6] H. L. Lee, K. C. So and C. S. Tang, "The value of information sharing in a two-level supply chain", Management science, http://dx.doi.org/10.1287/mnsc.46.5.626.12047, vol. 46, no. 5, (2000), pp. 626643.

[7] J. R. M. Torres and D. A. O. Vargas, "Collaboration and information sharing in dyadic supply chains: A literature review over the period 2000-2012. Gerenciales,.http://dx.doi.org/10.1016/j.estger.2014.05.006, vol. 30, no. 133, (2014), pp. 343-354.

[8] S. Cannella, "Order-Up-To policies in Information Exchange supply chains", Applied Mathematical Modelling,. http://dx.doi.org/10.1016/j.apm.2014.04.029, vol. 38, no. 23, (2014), pp. 5553-5561.

[9] S. J. Ryu, T. Tsukishima and H. Onari, "A study on evaluation of demand information-sharing methods in supply chain" International Journal of Production Economics,. doi:10.1016/j.ijpe.2008.07.030, vol. 120, no. 1, (2009), pp. 162-175.

[10] N. Shamir, "Strategic information sharing between competing retailers in a supply chain with endogenous wholesale price", International Journal of Production Economics, doi:10.1016/j.ijpe.2011.12.023, vol. 136, no. 2, (2012), pp. 352-365.

[11] J. Bian, X. Guo, K. K. Lai and Z. Hua, "The strategic peril of information sharing in a vertical-Nash supply chain: A note", International Journal of Production Economics, http://dx.doi.org/10.1016/j.ijpe.2014.07.016, vol. 158, (2014), pp. 37-43.

[12] A. Y. Ha, S. Tong and H. Zhang, "Sharing demand information in competing supply chains with production diseconomies", Management Science, doi 10.1287/mnsc.1100.1295, vol. 57, no. 3, (2011), pp. 566-581.

[13] Z. Li, S. M. Gilbert and G. Lai, "Supplier encroachment under asymmetric information", Management Science, http://dx.doi.org/10.1287/mnsc.2013.1780, vol. 60, no. 2, (2013), pp. 449-462.

[14] S. Li and B. Lin, "Accessing information sharing and information quality in supply chain management", Decision support systems, doi:10.1016/j.dss.2006.02.011, vol. 42, no. 3, (2006), pp. 1641-1656.

[15] S. H. Youn, M. G. M. Yang, J. H. Kim and P. Hong, "Supply chain information capabilities and performance outcomes: An empirical study of Korean steel suppliers", International Journal of Information Management, http://dx.doi.org/10.1016/j.ijinfomgt.2014.01.008, vol. 34, no. 3, (2014), pp. 369-380.

[16] W. H. J. Chu and C. C. Lee, "Strategic information sharing in a supply chain", European Journal of Operational Research,. doi:10.1016/j.ejor.2005.02.053, vol. 174, no. 3, (2006), pp. 1567-1579.

[17] H. Zhou and W. C. Benton, "Supply chain practice and information sharing", Journal of Operations management, http://dx.doi.org/10.1016/j.ijpe.2013.08.025, vol. 25, no. 6, (2007), pp. 1348-1365.

[18] D. W. Cho and Y. H. Lee, "The value of information sharing in a supply chain with a seasonal demand process", Computers \& Industrial Engineering, doi:10.1016/j.cie.2011.12.004, vol. 65, no. 1, (2013), pp. 97-108.

[19] C. M. Helper, L. B. Davis and W. Wei, "Impact of demand correlation and information sharing in a capacity constrained supply chain with multiple-retailers", Computers \& Industrial Engineering, doi:10.1016/j.cie.2010.06.014, vol. 59, no. 4, (2010), pp. 552-560.

[20] M. Shnaiderman and F. E. Ouardighi, "The impact of partial information sharing in a two-echelon supply chain", Operations Research Letters, http://dx.doi.org/10.1016/j.orl.2014.03.006, vol. 42, no. 3, (2014), pp. 234-237.

[21] L. Wu, C. H. Chuang and C. H. Hsu, "Information sharing and collaborative behaviors in enabling supply chain performance: A social exchange perspective", International Journal of Production Economics, http://dx.doi.org/10.1016/j.ijpe.2013.09.016, vol. 148, (2014), pp. 122-132.

[22] H. L. Lee, K. C. So and C. S. Tang, "The value of information sharing in a two-level supply chain", Management science, http://dx.doi.org/10.1287/mnsc.46.5.626.12047, vol. 46, no. 5, (2000), pp. 626643.

[23] S. Raghunathan, "Information sharing in a supply chain: A note on its value when demand is nonstationary", Management Science, vol. 47, no. 4, (2001), pp. 605-610. http://dx.doi.org/10.1287/mnsc.47.4.605.9833

[24] M. Kuby, S. Ratick and J. Osleeb, "Modeling US coal export planning decisions", Annals of the 
Association of American Geographers, 81(4), 627-649. DOI:10.1111/j.1467-8306.1991.tb01712.x, (1991).

[25] A. Zaklan, A. Cullmann, A. Neumann and C. V. Hirschhausen, "The globalization of steam coal markets and the role of logistics: An empirical analysis", Energy Economics, vol. 34, no. 1, (2012), pp. 105-116. doi:10.1016/j.eneco.2011.03.001.

[26] H. L. Lee and S. Whang, "Information sharing in a supply chain", International Journal of Manufacturing Technology and Management, DOI: 10.1504/IJMTM.2000.001329, vol. 1, no. 1, (2000), pp. 79-93.

[27] E. A. Silver and R. Peterson, "Decision systems for inventory management and production planning", Wiley series in production/operations management Show all parts in this series. http://tocs.ulb.tudarmstadt.de/59348216.pdf, (1985).

[28] M. Z. Babai, J. E. Boylan, A. A. Syntetos and M. M. Ali, "Reduction of the value of information sharing as demand becomes strongly auto-correlated", International Journal of Production Economics. doi:10.1016/j.ijpe.2015.05.005, (2015).

[29] R. Yan and Z. Pei, "Incentive information sharing in various market structures", Decision Support Systems. doi:10.1016/j.dss.2015.03.003, (2015). 